\title{
Risco para trauma vascular: proposta do diagnóstico e validação por peritos
}

\author{
Risk for vascular trauma: diagnosis proposal and validation by experts
}

Riesgo para trauma vascular: propuesta del diagnóstico y validación por peritos

\author{
Cristina Arreguy-Sena', Emília Campos de Carvalho" \\ 'Universidade Federal de Juiz de Fora. Juiz de Fora, $M G$ \\ "Universidade de São Paulo. Escola de Enfermagem de Ribeirão Preto. Ribeirão Preto, SP
}

Submissão: 14/01/2008

Aprovação: 3 1/10/2008

\section{RESUMO}

Pesquisa de validação conceitual e de conteúdo Que objetivou compor o título, os mecanismos de vulnerabilidade e os fatores de risco para o diagnóstico de enfermagem "Risco para Trauma Vascular", segundo a taxonomia da NANDA, bem como validar os elementos desse diagnóstico, a partir da opinião de 60 peritos. Foram identificados 51 fatores relacionados a cinco eixos: medicação e forma/ periodicidade de infusão; cateter intravascular e permanência num mesmo sítio; fixação do cateter intravascular; indivíduo, seus hábitos, padrão comunicacional, estilo de vida e capacidade sensório-motora; e decisões profissionais, política institucional e procedimento. Destes, foram validados 28 fatores de vulnerabilidade (escore e" 0,80). Os resultados evidenciaram "Risco para Trauma Vascular" ser um novo diagnóstico de enfermagem; sugere-se a validação clínica do mesmo.

Descritores: Enfermagem; Processos de enfermagem; Diagnóstico de enfermagem.

\section{ABSTRACT}

This concept and content validation study aimed to compose the title, vulnerability mechanisms and risk factors for the nursing diagnosis "Risk for Vascular Trauma", according to the taxonomy proposed by NANDA, as well as to validate the elements of this diagnosis, based on 60 experts' opinion. Fifty-one factors were identified, related to five axes: medication and infusion form/periodicity; intravascular catheter and dwelling in the same site; fixation of the intravascular catheter; individuals, their habits, communication standard, lifestyle and sensory-motor ability; and professional decisions, institutional policy and procedures. Among these, 28 vulnerability factors were identified (score e" 0.80). The results evidenced that "Risk for Vascular Trauma" is a new nursing diagnosis, and its clinical validation is suggested.

Descriptors: Nursing; Nursing process; Nursing diagnosis.

\section{RESUMEN}

Investigación de validación conceptual y de contenido con objeto de componer el título, los mecanismos de vulnerabilidad y los factores de riesgo para el diagnóstico de enfermería "Riesgo para Trauma Vascular", según la propuesta de la taxonomía de la NANDA, y también validar los elementos de ese diagnóstico, a partir de la opinión de 60 peritos. Fueron identificados 5 I factores relacionados a cinco ejes: medicación y forma/periodicidad de infusión; cateter intravascular y permanencia en un mismo sitio; fixación del cateter intravascular; individuo, sus hábitos, patrón comunicacional, estilo de vida y capacidad sensorio-motora; y decisiones profesionales, política institucional y procedimiento. De estos, fueron validados 28 factores de vulnerabilidad (score e" 0,80). Los resultados evidenciaron Que "Riesgo para Trauma Vascular" es un nuevo diagnóstico de enfermería; su validación clínica es sugerida.

Descriptores: Enfermería; Proceso de enfermería; Diagnóstico de enfermería. 


\section{INTRODUÇÃO}

O conhecimento dos vasos sangüíneos remonta à época de

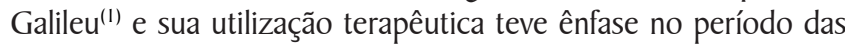
guerras com as tentativas de correção de volemia e com os ensaios de tansfusões, sendo a composição das soluções (concentração e $\mathrm{pH}$ ) e a falta de antissepsia e/ou esterilização componentes limitadores.

Contudo investigações sobre novos materiais e o desenvolvimento de técnicas e de habilidades para manipulá-los, possibilitaram aprofundar os conhecimentos sobre os vasos, o sangue e a veiculação das infecções ${ }^{(2,3)}$, realizar infusões intravascular ${ }^{(4)}$ e superar os tabus que envolviam a temática. Somamse ao surgimento de tecnologias aplicáveis à saúde, o conhecimento sobre: a fisiologia do sistema circulatório; tipos sanguíneos e suas (in)compatibilidades; tentativas exitosas de transferência de líeuidos e sangue; desenvolvimento de locais para acondicionamento e transferência de líquidos, nutrientes e sangue ${ }^{(5)}$; esclarecimento dos princípios farmacológicos implicados no uso dos vasos nas várias faixas etárias e situações clínicas e o desenvolvimento de habilidades para usá-los, fatores estes decisivos para viabilizar o uso terapêutico da via intravascular, conhecer seus limites, possibilidades e contra-indicações ${ }^{(6,7)}$.

Atualmente, a manipulação e a utilização dos vasos pelos profissionais da área de saúde para fins terapêuticos, farmacológicos, diagnósticos e paliativos estão alicerçadas na diversidade de equipamentos e soluções, no desenvolvimento de habilidades profissionais em lidar com materiais e equipamentos disponíveis no mercado e na variedade de cuidados disponibilizados. Do ponto de vista da atuação da Enfermagem, identificamos, simultaneamente, situações de vulnerabilidade para lesões dos vasos sanguíneos em uso e núcleos de ações terapêuticas (dentro da taxonomia da NIC- Nursing Intervention Classification) ${ }^{(8)}$ passíveis de evitarem sua instalação durante o "processo de punção vascular"(9). Diante do exposto, Questionamos até Que ponto as decisões adotadas por profissionais para escolher vasos, equipamentos e condições de uso/remoção, adequando-os à individualidade da clientela, interferem na instalação de traumas vasculares passíveis de prevenção?

\section{OBJETIVOS}

Propor o diagnóstico "Risco para trauma Vascular", a partir da validação por especialistas.

\section{REVISÃO BIBLIOGRÁFICA}

Cabe ao Enfermeiro executar, avaliar e acompanhar o processo de punção vascular, sendo o responsável pela manutenção da acessibilidade e/ou permeabilidade da via para os fins em curso Os dados obtidos em levantamento bibliográfico ( 1947 a 2007) e experiências das autoras no ensino e na prática clínica, tornou possível identificar diversas situações em Que as lesões dos vasos são passíveis de serem evitadas e/ou minimizadas.

Dentre as formas de evidenciamento de um vaso (percussão sobre o vaso; uso do esfignomanômetro bombeando-se até dois terços da pressão sistólica; movimentos de abrir e fechar a mão; posicionando da estrutura corporal dificultando retorno venoso; aplicação de compressas normas ou Quentes e elevação da temperatura em ambientes frios) ${ }^{(10)}$, o garroteamento tem sido a técnica mais usada na prática das punções venosas; contudo há recomendação para ajustar a pressão e o tempo de garroteamento, Quando se pretende evitar danos nos vasos ou nas áreas próximas a eles ${ }^{(11)}$.

Outra situação de possivel lesão de vaso, o emprego de cateteres intravasculares, teve, em decorrência de seus malefícios, aperfeiçoamento e favoreceu o surgimento de novos produtos ${ }^{(12)}$; independente do tipo de cateter, a relação entre seu calibre e o calibre do vaso, Quanto mais diferenciada, evitará flebites de origem física desencadeada pelo contato ${ }^{(13)}$. O registro do tipo e calibre do cateter e das condições da rede vascular nos protocolos institucionais, podem favorecer a identificação de situações hiatrogênicas, direcionar o conteúdo dos protocolos e das condutas institucionais e nortear processos educacionais ${ }^{(9)}$. Neste sentido, a formação profissional e/ou a aQuisição de habilidades por pessoas leigas são fundamentais para minimizar danos decorrentes do processo de punção vascular.

A transposição das camadas da pele pelo cateter rompe a barreira natural de proteção contra a invasão microbiana, tornando o local vulnerável à penetração de microrganismos patógenos ou oriundos da microbiota ${ }^{(14)}$, Que agirão sobre a(s) camada(s) interna e/ou externa do vaso, gerando: traumas supurativos (causados por agentes biológicos com veiculação direta ou indireta de tais germes) ou traumas não-supurativos (causados por alterações da coagulação, por agressões Químicas e/ou mecânicas) ${ }^{(15)}$.

O rompimento da pele aliado à debilidade orgânica/imunológica (característica do processo de adoecimento) e à exposição a ambientes com microbiota resistente (como é o caso do ambiente hospitalar) obtiveram destaque na década de $80^{(16)}$. Tais fatos fizeram com Que as flebites sépticas fossem denominadas de doenças negligenciadas ${ }^{(17)}$, ocorrendo sugestões de como preveni$\operatorname{las}^{(18)}$. O rompimento da técnica asséptica Que ocorre no uso autodeterminado de drogas intravasculares ou nas falhas técnicas são também situações Que vulnerabilizam os sítios de inserção dos dispositivos ou áreas adjacentes para a aQuisição de infecções ${ }^{(19)}$.

A existência de resíduos tóxicos no interior de materiais esterilizados (falha na esterilização) favorece a instalação de trauma nas estruturas corpóreas Que entram em contato com o equipamento(20). Embora a antissepsia seja estratégia capaz de minimizar infecções originadas da microbiota da pele, Quando o antisséptico entra em contato com a mucosa, pode causar trauma de origem Química $^{(21)}$.

Transfixar um vaso durante punção sem sucesso; retirar o cateter intravascular sem comprimir o local por tempo adequado ao processo de coagulação; aplicar torniQuete em sítio proximal a punção anterior ou deixar o "complexo de fixação" (equipamentos envolvidos na fixação do cateter e anexos) sem adesão ou frouxo geram traumas nos tecidos adjacentes evidenciados por hematomas ou equimoses ${ }^{(10)}$.

Neoplasias, gravidez, uso de contraceptivos e fitoterápicos são exemplos de componentes Que alteram o processo de coagulação e a imobilidade prolongada, as varizes, os pós-operatórios, as terapias intravasculares, o uso de solução irritante, o abuso de drogas não-lícitas injetáveis e as disfunções endoteliais (a exemplo 
das doenças de Behçet, Mondor e Buerger) favorecem a estase venosa $^{(22,23)}$. A equipe de enfermagem ao preparar, manusear e/ou infundir citostáticos intravasculares está exposta a riscos laborais, havendo recomendações para intensficar sua proteção ${ }^{(11)}$.

Dependendo da concentração e do $\mathrm{pH}$ das drogas, elas podem gerar danos no sítio de inserção/extravasamento ou no trajeto vascular, sendo classificadas em: vesicantes (aquelas Que desencadeiam necrose tecidual Quando extravasados) ou irritantes (aQuelas Que desencadeiam dor e reação inflamatória onde entram em contato $)^{(11)}$. Drogas infundidas em paralelo, vesicantes e irritantes, intensificam a vulnerabilidade para o trauma vascular a saber: Quimioterápicos ${ }^{(1)}$, contrastes $^{(24)}$; heparina e hidrocortisona ${ }^{(25)}$, dentre outras. Infundir droga sob pressão potencializa a ocorrência de lesões no epitélio vascular ${ }^{(26)}$, tornando o processo decisório a respeito da escolha das características do cateter fundamental para reduzir a agressão da íntima Quando haja compatibilização da concentração da droga com o calibre do vaso e do cateter.

A dificuldade em classificar os "fatores de risco" das lesões dos vasos ou suas áreas adjacentes possui origem multifatorial, sendo Que a "flebite" pode exemplificar diferentes origens de fatores desencadeantes do trauma, a saber: origem mecânica - devido ao tempo de permanência do garroteamento ou ao atrito do cateter com o vaso (favorecido pela frouxidão do complexo de fixação; pela proximidade entre os calibres e pelo posicionamento ou manuseio do cateter/equipamentos acessórios); origem Química em decorrência da droga (tipo/categoria, concentração, prazo de validade, pH, homogeneidade da solução; associações e interações medicamentosas), do diluente usado (tipo e volume), da velocidade de infusão (obter ou não tamponamento/hemodiluição) e do contato da solução anti-séptica com o interior do vaso e origem bacteriana - em decorrência da antissepsia da pele (remoção de germes colonizados), da ocorrência de contaminação (durante fabricação, transporte, armazenamento ou manuseio) das drogas, circuitos e equipamentos; da técnica de esterilização e acondicionamento do material (validade e adeQuação ao material) e pelo deslocamento bacteriano (concomitância com infecções generalizadas ou punção de sítios próximo à infecção), dentre outros ${ }^{(8-9)}$.

Os fatores de vulnerabilidade para lesão nos vasos e áreas adjacentes, Quanto as origens, identificados na literatura, podem ser sintetizados em: origem biológica - 1) técnicas assépticas de manuseio do sistema; contaminação de soluções durante preparo, acondicionamento, transporte, instalação do cateter e soluções, remoção dos equipamentos intravasculares e período de recuperação da integridade da pele (formação da ponte epitelial); 2) processo de esterilização; 3) controle biológico do material (controle de Qualidade na produção, acondicionamento, distribuição, armazenamento, manuseio e uso); 4) cuidados com a pele durante período em Que há o rompimento da barreira natural de proteção; 5) translocação de focos infecciosos e conseQüente colonização do cateter; 6) baixa de resistência imunológica do usuário (granulocitopenia temporária ou definitiva) e 7) tempo de troca do cateter e acessórios; origem (bio)Química - 1) concentração, pH e solubilidade da solução e forma de infusão (bolus, paralelo, etc.); 2) tipo e característica do material Que compõe os equipamentos (cateter, adesivos e acessórios); 3) existência de resíduos tóxicos no material esterilização; 4) processo de anti-sepsia; 5) diluição de drogas e interações entre elas; 6) freqüência de uso dos vasos; 7) resíduos de adesivo na pele após remoção do processo de fixação; 8) extravasamento de soluções vesicantes, irritantes ou neutras para estruturas adjacentes; 9) fluxo minuto sanguíneo insuficiente para promover tomponamento local da solução e 10) e 12) condições fisiológicas e/ou patológicas do usuário e origem física - 1) tempo de contato do cateter com um mesmo sítio de inserção; 2) grau de mobilidade/ consciência do usuário; 3) local de inserção do cateter; 4) forma de remoção do adesivo/esparadrapo da pele; 5) pressão na Qual uma solução adentra o vaso; 6) tipo de cateter; 7) relação entre o calibre do cateter e o diâmetro interno do vaso; 8) habilidade profissional para executar o processo de punção vascular; 9) modo, intensidade e duração do processo de evidenciamento do vaso; 10) distensão de compartimentos virtuais por volumes de líeuidos; 1 I) perfuração de estruturas adjacentes ao(s) vaso(s) e 12) características do vaso selecionado para punção ${ }^{(9)}$. Esses fatores foram considerados na presente proposta, porém com denominações de categorias distintas, como se verá a seguir.

\section{MÉTODO}

Pesquisa clínica, de validação de diagnóstico a partir da técnica Delphi ${ }^{(27,28)}$ e do modelo de validação de conteúdo (DCV) de Fehring ${ }^{(29,30)}$, contendo cinco etapas: 1) levantamento bibliográfico; 2) elaboração do título e de seu conceito; 3) construção das justificativas dos mecanismos de vulnerabilidade para subsidiar o parecer dos peritos; 4) definição dos escores dos fatores de risco extraído da opinião dos peritos e 5) classificação dos fatores de risco a partir do ponto de corte adotado. Realizamos levantamento bibliográfico nas bases de dados LILACS e Medline inicialmente no período de 1944 a 2001 e, posteriormente, até 2007, não sendo observado novos elementos para a composição do diagnóstico; essa etapa possibilitou a obtenção de sustentação teórica capaz de contextualizar a existência de um possível diagnóstico de risco para a temática das punções de vasos, na perspectiva dos problemas de enfermagem passíveis de serem prevenidos. Instrumento de coleta de dados (caracterização dos participantes; titulo do diagnóstico e sua definição; lista de "situações/circunstâncias de risco" com suas respectivas justificativas de vulnerabilidade) Que teve todo o conteúdo validado até a obtenção de consenso unânime entre cinco peritos e agrupadas em eixos por afinidade de conteúdo. Na lista de "situações/ circunstâncias de risco" incluímos duas Questões de confusão (a respeito da medicação e do cateter intravascular). Após a validação aparente do instrumento, o mesmo foi apresentado a 60 peritos, oriundos das cinco regiões brasileiras, Que obtiveram escore compreendido entre sete a 11 pontos ${ }^{(29,30)}$. Os dados foram coletados de março a dezembro de 2001, com escala Likert contendo cinco pontos. Calculamos o valor do escore total de validação do fator de risco e do diagnóstico; embora haja a recomendação para ponto de corte de $0,50^{(29,30)}$ e $0,60^{(31)}$, adotamos o valor de 0,80 .

\section{RESULTADOS E DISCUSSÃO}

O levantamento bibliográfico evidenciando a ausência de um 
diagnóstico de enfermagem capaz de contemplar a situação de vulnerabilidade para ocorrência de trauma nos vasos sanguíneos motivou-nos a apresentá-lo, conforme a proposta da NANDANorth American Nursing Diagnosis Association ${ }^{(32)}$.

Proposta de inserção do diagnóstico - Partindo da taxonomia II da NANDA e analisando os eixos e/ou elementos Que compõem um diagnóstico à luz do delineamento da presente proposta, usamos as expressões "risco", "trauma" e "vascular" localizadas nos seguintes eixos: "estado de saúde" (Quinto da taxonomia); "conceito diagnóstico" (primeiro eixo) e "topologia" (sétimo eixo), respectivamente, acrescidos pela preposição "para" como estrutura conectora. Cabe destacar Que em virtude do presente diagnóstico ser "potencial" e ocorrer com um indivíduo em Qualquer idade ao longo do ciclo da vida, fez com Que não incluíssemos os eixos "tempo" (segundo da taxonomia), "sujeito do diagnóstico" (terceiro da taxonomia), "idade" (Quarto da taxonomia) e "descritor" (sexto da taxonomia) $)^{(32)}$.

Título do diagnóstico - Tendo em vista Que "trauma vascular"(8) possui terminologia coerente com o enfoque da temática e é passível de retratar o diagnóstico de risco para traumas potenciais que ocorrem nos vasos sanguíneos, áreas adjacentes e Que apresentam efeitos locais ou sistêmicos em decorrência do "processo de punção vascular", optamos pelo título "Risco para trauma vascular" por considerá-lo adequado; este titulo obteve concordância unânime dos peritos.

Definição do diagnóstico - Estado no qual o indivíduo apresenta suscetibilidade para danos internos ou externos ao vaso ou áreas próximas a ele de origem química e/ou bioquímica e/ou física e/ou biológica, em uma ou várias camadas teciduais/tecidos subjacentes, decorrentes do uso do cateter e/ou líquidos infundidos ou drenados. Esta definição obteve concordância unânime dos peritos.

Fatores de risco, mecanismos de vulnerabilidade e escores Dentre os fatores de risco de cada eixo, 28 obtiveram escores igual ou superior a $80 \%, 19$ evidenciaram ser fatores de vulnerabilidade passível de promoverem tal diagnóstico (escores $>0,50$ e $<080$ ) e dois evidenciaram pouca possibilidade de desencadearem tal diagnóstico, segundo os peritos Que os analisaram (escores $<0,50$ ).

Nos Quadros 1 e 2, apresentamos os fatores de risco (com escores $>0,80$ ) para as difrentes situações (eixos) relacionadas ao diagnóstico proposto com a explicitação do mecanismo de vulnerabilidade, a pontuação e média de escores obtidos.

Para os nove fatores de risco a respeito da medicação e da forma/periodicidade de infusão, obtivemos cinco fatores de risco com escores e" 0,80 , além de outros três fatores de risco com escores e" 0,72 e $<0,80$, não incluídos na presente proposta, a saber: Temperatura de infusão de líeuidos; Periodicidade e intervalo de infusão; Forma e periodicidade do controle de vazão e do local de aplicação. O fator cor da droga apresentou escore inferior a 0,50 . Frente a esses dados o escore geral dos fator de risco deste eixo foi de 0,78 .

Cabe lembrar Que a irritação vascular ou ocorrência de dor no sítio de inserção de um cateter intravascular podem ser causadas por extremos do pH das soluções em relação ao pH sanguíneo ou Quando há concentrações superiores a $40 \mathrm{mEQ} / \mathrm{l}$ de drogas como: cloreto de potássio, fenitoína e alguns antibióticos (vancomicina, eritromicina e nafcilina), cabendo destacar Que situações como é o caso da forma de armazenagem, estocagem, validade da droga e acréscimo de aditivos (exemplo: "vitamina C", doxorrubina e a cimetidina) podem alterar o $\mathrm{pH}^{(10)}$. Os exemplos clássicos de lesões vasculares decorrentes do tipo de drogas são: 1) glicose hipertônica $^{(33)}$; 2) diclofenaco ${ }^{(34)}$; 3) difenil hidantoína ${ }^{(35)}$; 4) diazepan $^{(36)}$; 5) praxilene ${ }^{(37)}$; 6) epoprostenol ${ }^{(38)}$; 7) anfotericina $\mathrm{B}^{(39)}$, além das lesões desencadeadas pela velocidade de infusão ${ }^{(40)}$.

Para os cinco fatores de risco relacionados ao cateter intravascular e a sua permanência num mesmo sítio de inserção, obtivemos três fatores de risco com escores e" 0,80 (quadro 2); foi ainda observado o fator de risco Material de composição da agulha do cateter com escore 0,77 e cor do dispositivo com escore $<0,50$. Frente a essse dados, o escore geral dos fatores deste eixo foi de 0,77 .

A escolha do tipo e do calibre do cateter pode intensificar ou minimizar traumas vasculares ${ }^{(10.13)}$, sendo desaconselhável, do ponto de vista da vulnerabililidade para instalação de trauma vascular, o uso de cateteres com calibres próximos ao vaso, embora a "Lei de Poisaille" possa justificar o uso de cateteres curtos e de grande calibre (14G ou 16G em vias periféricas) em situações de emergência com vistas a obtenção de reposições volêmicas de até $120 \mathrm{ml} /$ minuto $^{(4 I)}$.

A respeito da fixação do cateter intravascular, foram estudados cinco fatores de risco; obtivemos dois com escores e" 0,80 , além de três outros com escores compreendido entre 0,73 e 0,80 , não incluídos na presente proposta de diagnóstico; são eles: Impossibilidade de visualização da(s) área(s) adjacente(s) ao sítio de inserção do cateter $=0,79$; Tempo prolongado de permanência dos mesmos adesivos e seus resíduos num mesmo sítio $=0,77$; Excesso de pêlos e/ou comprimento longo dos mesmos no sítio de fixação $=0,73$. Frente a esses dados, o escore geral dos fatores desse eixo foi de 0,80 .

A diversidade de materiais (esparadrapo comum, hipoalérgico ou antialérgicos, membranas impermeável ou semipermeável, ataduras ou bandagens, dentre outros) ${ }^{(42)}$ utilizada para fixação do cateter intravascular e seus acessórios visa diminuir: à movimentação da agulha no interior do vaso; o extravasamento de soluções para tecidos adjacentes e à possibilidade de transfixação do vaso (decorrrente do contato da ponta da agulha com as camadas do vaso), além de prevenir a ocorrência de micro e macro traumas ${ }^{(13)}$ e a impossibilidade de visualizar o sítio de inserção do cateter e as áreas adjacentes dificulta a identificação precoce de alterações locais $^{(43)}$

Para os 12 fatores de risco propostos a respeito do indivíduo, seus hábitos, padrão comunicacional, estilo de vida e capacidade sensório-motora, obtivemos seis fatores de risco com escores $>0,80$; outros Quatro fatores obtiveram escores e" 0,65 e $<0,80$ (Ausência de comunicação ou comunicação ineficaz de dor ou desconforto restrita ao sítio do cateter, áreas adjacentes e trajeto vascular, durante uso=0,79; Punção vascular em estrutura corporal Que apresente imobilidade, restrição parcial ou total por autodeterminação ou incapacidade de evitá-la $=0,78$; Falta de participação efetiva da pessoa Que se encontra com o vaso puncionado ou de seu acompanhante na avaliação contínua do local de inserção do cateter intravascular $=0,71$; e Tabagis$\mathrm{mo}=0,65$ ); outros dois apresentaram valores $<0,50$ : Uso de hormônio para contracepção, tratamento ou por autodeterminação 


\begin{tabular}{|c|c|c|c|c|}
\hline Eixo & Fatores de risco & Mecanismo de Vulnerabilidade & Pontos & $\begin{array}{c}\text { Média de } \\
\text { escores }\end{array}$ \\
\hline \multirow{5}{*}{ 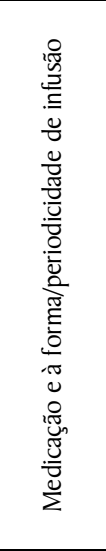 } & $\begin{array}{l}\text { Concentração e/ou diluição da } \\
\text { droga ser incompatível com seu } \\
\text { tamponamento ou sua } \\
\text { hemodiluição }\end{array}$ & $\begin{array}{l}\text { Quanto mais concentrada, pouco diluída ou não diluída for/estiver a } \\
\text { droga maior será a dificuldade dela se dissolver no sangue e maior a } \\
\text { possibilidade de causar irritação. }\end{array}$ & 56,2 & 0,93 \\
\hline & $\begin{array}{l}\text { Toxicidade e fator mutagênico } \\
\text { da droga (ser vesicante intra ou } \\
\text { extravascular) }\end{array}$ & $\begin{array}{l}\text { Quando uma droga vesicante ou irritante entra em contato com a } \\
\text { íntima ou com o espaço extravascular há chances dela causar lesão } \\
\text { nessa(s) estrutura(s) Quando comparada com drogas não vesicantes } \\
\text { (exemplo: infusão de Quimioterápicos). }\end{array}$ & 55,7 & 0,92 \\
\hline & Tempo de infusão da droga & $\begin{array}{l}\text { Infusões de drogas ou volumes superior a } 90 \mathrm{ml} / \text { hora intensificam as } \\
\text { chances de trauma vascular Quando comparadas a infusões de } \\
\text { volume/minuto menores. }\end{array}$ & 50,5 & 0,84 \\
\hline & pH do líquido infundido & $\begin{array}{l}\text { Drogas com pH fora da acidez recomendada }(3,5 \text { a } 6,2) \text { intensificam } \\
\text { as chances de lesões na íntima, pois Quando maior a acidez da } \\
\text { solução maior a irritabilidade tecidual. }\end{array}$ & 48,7 & $0,8 \mathrm{I}$ \\
\hline & $\begin{array}{l}\text { Tipo/categoria a Que a droga } \\
\text { pertence }\end{array}$ & $\begin{array}{l}\text { Determinadas categorias farmacológicas desencadeiam chances de } \\
\text { dano vascular (exemplo: difenilhidantoína). }\end{array}$ & 48,5 & 0,80 \\
\hline \multirow{3}{*}{ 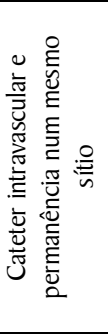 } & $\begin{array}{l}\text { AdeQuação da relação entre o } \\
\text { calibre do cateter e o do vaso }\end{array}$ & $\begin{array}{l}\text { Calibre externo do cateter próximo ao calibre do vaso reduz o fluxo } \\
\text { sanguíneo pericateter e intensifica o atrito entre ambos. }\end{array}$ & 52,2 & 0,87 \\
\hline & $\begin{array}{l}\text { Tempo de permanência do } \\
\text { cateter num mesmo sítio de } \\
\text { inserção }\end{array}$ & $\begin{array}{l}\text { Tempo aumentado de permanência de um cateter num mesmo sítio } \\
\text { de inserção intensifica as chances de desenvolvimento de flebite, } \\
\text { trombofebrite e infecção. }\end{array}$ & 52 & 0,86 \\
\hline & $\begin{array}{l}\text { Tipo de cateter intravascular } \\
\text { usado }\end{array}$ & $\begin{array}{l}\text { Cateteres periféricos com agulha rígida (metálica) intensificam as } \\
\text { chances de ocorrer transfixação do vaso e a permanência de cateteres } \\
\text { com agulha flexível aumenta o risco de irritação da íntima do vaso por } \\
\text { atrito. }\end{array}$ & 49 & 0,81 \\
\hline \multirow{2}{*}{ 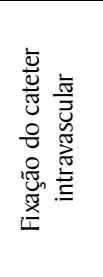 } & $\begin{array}{l}\text { Mobilidade do complexo de } \\
\text { fixação do cateter intravascular }\end{array}$ & $\begin{array}{l}\text { A mobilidade do complexo de fixação intensifica o contato da agulha } \\
\text { com a parede do vaso e possibilita seu deslocamento (parcial ou } \\
\text { total). }\end{array}$ & 55,2 & 0,92 \\
\hline & $\begin{array}{l}\text { Tipo e eualidade do material } \\
\text { utilizado na fixação do cateter } \\
\text { intravascular. }\end{array}$ & $\begin{array}{l}\text { Determinados tipos de adesivos (tecidual, sintético, bandagem, } \\
\text { membranas) apresentam chances para desenvolver reações alérgicas e } \\
\text { a Qualidade do material (capacidade de aderência à pele e } \\
\text { impregnação residual após a remoção) intensifica ou não o contato da } \\
\text { cola com a pele ou dificultar sua remoção. }\end{array}$ & 49 & 0,81 \\
\hline \multirow{6}{*}{ 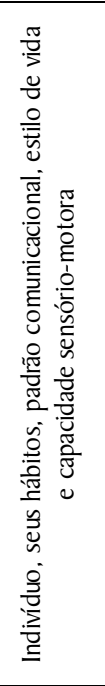 } & $\begin{array}{l}\text { Infecção(ões) da pele em sítio(s) } \\
\text { próximo(s) à instalação do } \\
\text { cateter intravascular }\end{array}$ & $\begin{array}{l}\text { A proximidade do sítio de inserção do cateter com áreas com foco } \\
\text { infeccioso, colonizadas ou com solução de continuidade da pele pode } \\
\text { intensificar as chances de trauma vascular por deslocamento de } \\
\text { germes. }\end{array}$ & 54,5 & 0,90 \\
\hline & $\begin{array}{l}\text { Punção vascular realizada em } \\
\text { pessoas com extremos de idade }\end{array}$ & $\begin{array}{l}\text { Os vasos, ao longo do ciclo da vida, apresentam características } \\
\text { morfofuncionais peculiares a cada fase, interferindo nas chances de } \\
\text { ocorrência de trauma vascular }\end{array}$ & 53,2 & 0,88 \\
\hline & $\begin{array}{l}\text { Condições de saúde, } \\
\text { tratamento e diagnóstico }\end{array}$ & $\begin{array}{l}\text { Condições de saúde e tratamento em curso por si só já desencadeiam } \\
\text { (in)diretamente trauma vascular (exemplo: fístula arteriovenosa, estase } \\
\text { venosa, distúrbio de coagulação e dislipidemia). }\end{array}$ & 53,2 & 0,88 \\
\hline & Tipo/característica do vaso & $\begin{array}{l}\text { A caracterização do vaso pode dificultar o processo de punção ou } \\
\text { manutenção do cateter (exemplo: veia tortuosa e com peQueno calibre } \\
\text { intensificam as chances de transfixação ou contato do cateter com o } \\
\text { vaso). }\end{array}$ & 51 & 0,85 \\
\hline & $\begin{array}{l}\text { Alergia à solução anti-séptica } \\
\text { e/ou ao adesivo }\end{array}$ & $\begin{array}{l}\text { Há pessoas Que são alérgicas às soluções anti-sépticas e aos adesivos } \\
\text { ou Que os desenvolvem pelo uso. }\end{array}$ & 51 & 0,85 \\
\hline & $\begin{array}{l}\text { Abuso de droga intravascular } \\
\text { por autodeterminação }\end{array}$ & $\begin{array}{l}\text { Uso autodeterminado de drogas injetáveis expõe ao consumo de } \\
\text { substâncias pouco purificadas, não estéreis, contaminadas, diluídas } \\
\text { em peQuenos volumes e aplicadas sem anti-sepsia e Quando usadas } \\
\text { em doses cumulativas aumentam as chances de extravasamento. }\end{array}$ & 50,5 & 0,84 \\
\hline
\end{tabular}

Nota das autoras: * $H D L-C=$ lipoproteínas de alta densidade e $L D L-C=$ lipoproteínas de baixa densidade.

\section{Quadro 1. Fatores de risco e mecanismos de vulnerabilidade para o diagnóstico} de "Risco para trauma vascular".Juiz de Fora, 2002.

e Tipo de atividade/ocupação exercida por tempo prolongado antes do processo de punção vascular. Frente a esses dados, o escore geral dos fatores desse eixo foi de 0,73 .

O processo do envelhecimento celular repercute sobre os vasos (cujas camadas perdem colágeno) e sobre as válvulas (Que se deterioram), dando aos vasos e ao seu trajeto, do ponto de vista clínico, características de tortuosidade e de nodulosidade (incompetência valvular) $^{(13)}$. Destacamos as condições mórbidas Que intensificam os traumas venosos: alterações plaquetárias ${ }^{(23,44)}$; tríade de Virchow (estase venosa, lesão endotelial e alterações dos 


\begin{tabular}{|c|c|c|c|c|}
\hline Eixo & Fatores de risco & Mecanismo de Vulnerabilidade & Pontos & $\begin{array}{l}\text { Média de } \\
\text { escores }\end{array}$ \\
\hline \multirow{12}{*}{ 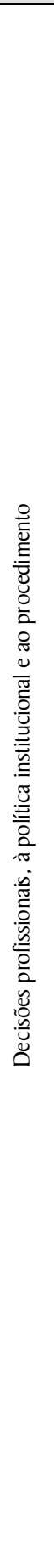 } & $\begin{array}{l}\text { Punção de um vaso em local } \\
\text { próximo a lesão. }\end{array}$ & $\begin{array}{l}\text { Uso prolongado da via intravascular restringe progressivamente as } \\
\text { opções de vasos para punção, fazendo com eue eles sejam } \\
\text { repuncionados e o cateter inserido em pontos distintos de um mesmo } \\
\text { vaso. }\end{array}$ & 56,75 & 0,94 \\
\hline & Qualidade do material usado & $\begin{array}{l}\text { A Qualidade e especificação do material usado no processo de punção } \\
\text { vascular (exemplo: bisel não facetado, extravasamento de líouidos no } \\
\text { circuito) podem intensificar as chances de trauma vascular. }\end{array}$ & 55,52 & 0,92 \\
\hline & $\begin{array}{l}\text { Número de punções } \mathrm{e} \\
\text { repunções intravasculares }\end{array}$ & $\begin{array}{l}\text { O uso prolongado da via intravascular como alternativa terapêutica } \\
\text { reQuer a rotatividade nos sítios de inserção dos cateteres. }\end{array}$ & 55 & 0,91 \\
\hline & $\begin{array}{l}\text { Reiniciar a infusão após a } \\
\text { ocorrência de coágulo no } \\
\text { sistema ou presença de } \\
\text { sangramento no circuito, sem } \\
\text { Que haja a devida remoção. }\end{array}$ & $\begin{array}{l}\text { O refluxo sanguíneo para o interior do circuito de infusão pode formar } \\
\text { (micro)coágulo e euando visíveis (vermelhos vivos) são removidos e } \\
\text { Quando não visíveis (rósea) podem ser reintroduzidos para dentro do } \\
\text { sistema circulatório, aumentando as chances de trauma vascular em } \\
\text { pessoas com predisposição para formar trombos. Situações como: } \\
\text { diluiçãa da droga (água destilada desencadeia hemólise e glicose irrita } \\
\text { a íntima); punção de vasos com alto volume/minuto e uso de circuitos } \\
\text { longos favorecem a ocorrência dos traumas. }\end{array}$ & 54,5 & 0,90 \\
\hline & $\begin{array}{l}\text { Inclinação da agulha em relação } \\
\text { à pele durante a remoção da } \\
\text { mesma }\end{array}$ & $\begin{array}{l}\text { Falta de flexibilidade e de adequação do mobiliário hospitalar às } \\
\text { peculiaridades dos trabalhadores pode gerar a inclinação da agulha } \\
\text { em relação à pele durante a remoção da mesma, o Que intensifica as } \\
\text { chances de trauma do vaso. }\end{array}$ & 54,25 & 0,90 \\
\hline & $\begin{array}{l}\text { Tracionamento do cateter } \\
\text { intravascular }\end{array}$ & $\begin{array}{l}\text { Deslocamento parcial/total da agulha de dentro do vaso ou retenção } \\
\text { do circuito em superfícies (roupas ou objetos) é suficiente para } \\
\text { tracionar acidentalmente o cateter e provocar extravasamento de } \\
\text { líeuido/sangue. }\end{array}$ & 54 & 0,90 \\
\hline & Técnica de esterilização & $\begin{array}{l}\text { Visualização de corpo estranho é sugestivo de contaminação e as } \\
\text { condiçôes de armazenamento, transporte, acondicionamento intra e } \\
\text { extra-setorial e manuseio interferem na esterilização do material. }\end{array}$ & 53 & 0,88 \\
\hline & $\begin{array}{l}\text { Posicionamento corporal } \\
\text { comprimindo o local em Que há } \\
\text { a punção vascular }\end{array}$ & $\begin{array}{l}\text { O posicionamento corporal (deitar sobre o local ou mantê-lo } \\
\text { flexionado por tempo prolongado) pode, ao comprimir a estrutura } \\
\text { corporal, interromper temporariamente a infusão de líquidos } \\
\text { (desencadeando obstrução parcial ou total), transfixar o vaso (euando } \\
\text { é usado dispositivo de agulha rígida) e aumentar a pressão } \\
\text { intravascular (principalmente ao redor do cateter). }\end{array}$ & 52,25 & 0,87 \\
\hline & $\begin{array}{l}\text { Manutenção do cateter num } \\
\text { mesmo sítio por um período } \\
\text { superior ao recomendado na } \\
\text { literatura. }\end{array}$ & $\begin{array}{l}\text { Condições de saúde dos indivíduos podem requerer Que, por medida } \\
\text { de segurança ou terapêutica, um vaso seja mantido puncionado (pela } \\
\text { técnica de heparinização, salinização ou infusão contínua) por um } \\
\text { período superior ao recomendado na literatura, havendo } \\
\text { intensificação da vigilância do sítio de inserção e das áreas adjacentes } \\
\text { para deteç̧ão precoce dos primeiros sinais e sintomas de trauma } \\
\text { vascular. }\end{array}$ & 51 & 0,85 \\
\hline & $\begin{array}{l}\text { Localização do sítio de inserção } \\
\text { de um cateter intravascular }\end{array}$ & $\begin{array}{l}\text { Hemodiluição da droga, volume/minuto infundido, pressão } \\
\text { intravascular, liberdade de movimentaçãa do indivíduo, contato do } \\
\text { cateter com a parede do vaso e transfixação do vaso são influenciados } \\
\text { pelo local de inserção do cateter (exemplo: articulação). }\end{array}$ & 50,5 & 0,84 \\
\hline & Limpeza e preparo da pele & $\begin{array}{l}\text { Rotinas e protocolos institucionais de seleção dos anti-sépticos } \\
\text { usados no preparo da pele durante punções vasculares nem sempre } \\
\text { dão cobertura para colonização da pele por Stafilococus aureus } \\
\text { coagulase positiva, (cursam sem sintomatologia e aumentada na } \\
\text { populações não institucionalizadas). }\end{array}$ & 50 & 0,83 \\
\hline & $\begin{array}{l}\text { Número de equipamentos } \\
\text { conectados ao cateter }\end{array}$ & $\begin{array}{l}\text { Desproporção entre os equipamentos conectados (in)diretamente ao } \\
\text { cateter intravascular, afrouxamento das conexões pela movimentação } \\
\text { e manuseio/exposição das conexões podem desencadear } \\
\text { extravasamento de líquido, contaminação ou entrada de ar no sistema. }\end{array}$ & 48,25 & 0,80 \\
\hline
\end{tabular}

Quadro 2. Fatores de risco para ocorrência de "Risco para trauma vascular", segundo o eixo ligado às decisões profissionais, à política institucional $\mathrm{e}$ ao procedimento, mecanismo de vulnerabilidade, pontuação acumulada com peso $\mathrm{e}$ média de escores. Juiz de Fora, 2002.

componentes do sangue) ${ }^{(45)}$ e farmacodependência intravascular. $\mathrm{O}$ consumo do tabaco intensifica o risco de tromboflebites ${ }^{(46)}$.

Para os 20 fatores de risco a respeito das decisões profissionais, da política institucional e do procedimento propriamente dito, obtivemos 12 fatores de risco com escores e"0,80 e oito com escores e"0,55 e $<0,80$ (Periodicidade de manuseio ou uso do vaso; Forma e duração do evidenciamento do vaso; Controle do sistema de vazão de líeuidos; Resíduo de solução anti-séptica na ocasião em Que a agulha é introduzida; Relação entre o número de vias disponíveis e em uso efetivo; Uso/manuseio e frequência de 
(des)clampeamento do sistema; Uso de extensor de via. Imobilização parcial e/ou total indicada para tratamento ). O valor do escore geral dos fatores desse eixo foi de 0,79 .

Apesar da regulamentação dos materiais usados nas instituições de saúde ser feita pela Associação Brasileira de Normas Técnicas ${ }^{(47-}$ ${ }^{52)}$, definir a escolha dos materiais e dos equipamentos hospitalares é complexo pois, além de refletir as relações institucionais e a influência de marketing das empresas fornecedoras, deve envolver avaliação e inserção dos profissionais Que o manipulam e dos usuários para assegurar Qualidade, conforto e segurança, uma vez Que o uso do preço como critério prioritário para sustentar a aQuisição, nem sempre assegura Que as normas técnicas e o bemestar sejam cumpridos ${ }^{(9,53,54)}$.

\section{CONCLUSÕES}

A proposta do diagnóstico de enfermagem "Risco para trauma vascular" evidenciou ser o mesmo passível de inclusão na taxonomia da NANDA. A validação conceitual e de conteúdo dos título e sua definição obtiveram 100\% de concordância entre os peritos. Dos 51 possíveis fatores de riscos apresentados aos peritos, identificamos consistência para vulnerabilidade do trauma vascular nos cinco eixos 1 - medicação e à forma/periodicidade de infusão; 2- cateter intravascular e permanência num mesmo sítio; 3- fixação do cateter intravascular; 4) indivíduo, seus hábitos, padrão comunicacional, estilo de vida e capacidade sensório-motora e 5decisões profissionais, política institucional e procedimento. Dentre os fatores de risco de cada eixo, 28 obtiveram escores igual ou superior a $80 \%$, escore adotado como ponto de corte para a presente proposta. Diante do exposto, o diagnóstico, obteve escore total de 0,77 , considerado satisfatório para esse tipo de validação.

\section{RECOMENDAÇÕES}

Sugerimos novos estudos de validação por peritos para os fatores de risco Que obtiveram escores compreendidos entre 0.50 e 0.79 , podendo-se observar amostras especificas, bem como a validação clínica com amostras significativas.

\section{REFERÊNCIAS}

1. Gordon N. O físico: uma epopéia de um medico medieval. $15^{\mathrm{a}}$ ed. Rio de Janeiro: Rocco; 1988.

2. Ingraham FC, Alexander-Jr E, Matson DD. Polyethylene, a new synthetic plastic for use in surgery. JAMA 1947; 135(2): 827.

3. MacFayen WAI. Preparations and applications: heparin administration by polythene tubing. Br Med I 1949; 2: 925-6.

4. Meyers L. Intravenous catheterization. Am I Nurs 1945; 45(2): 930-1.

5. Liu JC. The Chinese blood bank in Lumming. Am I Nurs 1945; 45(9):686-7.

6. Black M, Carré IJ, Wolff OH Scalp-vein transfusion in infants. Lancet 1951: 19-20.

7. Arreguy-Sena C, Carvalho ECC. Avaliação de punção venosa periférica: análise de critérios de remoção de dispositivo intravenoso adotados por uma equipe de enfermagem. Esc Anna Nery Rev Enferm 2003; 7(3): 35 I-60.

8. Arreguy-Sena C, Carvalho ECC. Trauma vascular: proposição dos elementos do diagnóstico e validação de conteúdo por peritos. Rev Pensar Enferm 2007; II (1): 12-23.

9. Arreguy-Sena C. A trajetória de construção e validação dos diagnósticos de enfermagem "Trauma Vascular" e "Risco para Trauma Vascular" [tese]. Ribeirão Preto: Escola de Enfermagem de Ribeirão Preto, Universidade de São Paulo; 2002.

10. Phillips LD. Manual de terapia intravenosa. $2^{\mathrm{a} e d}$. Porto Alegre: Artmed; 2001.

11. Silva ACP. Extravasamento de drogas vesicantes: relato de experiência. Rev Paul Enferm 1992; I I(1): 27-9.

12. Wigness BD, Dorman FD, Fohde TD, Buchwald H. In vitro and in vivo testing of a new valved intravesnous catheter design. ASAIO Trans 1990; (37): 355-8.

13. Polimeno NC, Hara MH, Appezzato LF, Fernandes V, Cintra LA, Hara CA. Incidência e caracterização da tromboflebite superficial (TFS) pós-venóclise em Hospital Universitário. I Bras Med 1995; 69(3): 196-204.
14. Utyama IKA, Ohnishi M, Quesada RMB, Ishiota $\mathrm{CH}$, Investigação de enfermagem sobre o uso de cateteres venosos em clientes hospitalizados. Rev Bras Enferm 1997; 50(2): 291-6.

15. Torrejón EM. Cateterizaciones venosas centrales: complicaciones. Rev Med Inst Peruano Seg Soc 1992; I(2): 10-5.

16. Bonilla IC, González A, Gómez E. Cateteres venous centrales : evolución de 310 cateteres colocados en el Hospital Universitário del Valle. Colombia Médica 1988; 19(2): 6872.

17. Baker CC, Petersen SR, Sheldon GF Septic phlebitis: a neglected disease. Am I Surg 1979; 138: 97-102.

18. Cremshaw CA, Kelly LR, Turner RJ, Eneas D. Bacteriologic nature and prevention of contamination to intravenous catheters. Am I Surg 1972; (123): 264-6.

19. Barg N, Supena RB, Fekety R Persistent staphulococcal bacteremia in an intravenous drug abuser. Antim Agents Chem 1986; 29(2): 209-11.

20. Marcel YL, Noel SP. Contamination of blood stored in plastic packes. Lancet 1970; 35-6.

21. Sieunarine K, White GH. Full-thickness burn and venous thrombosis following intravenous infusion of microwave-heated crystalloid fluids. Burns 1996; 22(7): 568-9.

22. Lastória S. Thrombophebite superficial: In: Maffei FHA et al. Doenças Vasculares periféricas. $2^{\mathrm{a} e d . ~ S a ̃ o ~ P a u l o: ~ M E D S I ; ~}$ 1995. p. 831-40.

23. Nicoletti MA, Oliveira-Ir MA, Bertasso CC, Caporossi PY, Tavares APL. Principais interações no uso de medicamentos fitoterápicos. Informa 2007; 19(1/2): 32-40.

24. Maffei FHA, Rolla HÁ, Fabris VE. Prevention of experimental venous thrombosis induced by contrast medium em the rat. Acta Radiol Diag 1980; 21 (2A): 249-52.

25. Bassan MM, Sheilh-Haamad D. Prevention of lidocaine-infusion phlebitis by heparin and hydrocortisone. Chest 1983; 84(4):439-4I. 
26. Hessov IB, Allen I, Kersten A, Gravholt L. Infusion thrombophebitis in a surgical department. Acta Chir Scan 1977; 143: 15 I-4.

27. Schell KA. A Delphi study of imovative teaching in Baccalaureate nursing education. I Nurs Educ 2006; 45(1 I): 439-48.

28. Powell Catherine Methodological issues in nursing research: the Delphi techinique: myths and realities. I Adv Nurs 2004; 4I (4): 376-82.

29. Fehring RJ. Methods to validate nursing diagnosis. Heart \& Lung 1987; 16(6): 625-9.

30. Hurley ME. Classification of nursing diagnoses: proceedings of the sixth conference. Saint Louis: Mosby; 1986.

31. Sparks SM, Lien-Gieschen T. Modification of the diagnostic content validity. Nurs Diag 1994; 5 (1): 3 I-5.

32. North American Nursing Diagnosis Association. Diagnósticos de enfermagem da NANDA: definições e classificação 2005 2006. Porto Alegre: Artmed; 2006.

33. Vallerand A, Kavanagh MF. Thrombophebitis folling intravenous glucose in the cold. Av Spa Env Med 1989; 349-5 I.

34. Gopinath R. Veous sequele after i.v. diclofenac. $\mathrm{Br}$ I Anaest 1991; 67: 803-4.

35. Spengler RF, Arrowsmith JB, Kilarski DF, Buchanan C, Behren LV, Graham DR. Severe soft-tissue injury following intravenous infusion of phenytoin. Arc Inter Med 1988; 148: 1329-33.

36. Olesen AS, Hüttel MS. Local reactions to i.v. diazepam in three different formulations. Br I Anaest 1980; 52: 609-11.

37. Woodhouse CRI, Eadie DGA. Severe thrombophlebitis with praxilene. Br Med I 1977; I: 1320.

38. Yardumian DA, Machin SI. Altered plateled funciont in patients on continous infusions of epoprostenol. Lancet 1984; 16:1357.

39. Fujiwara T, Kawarasaki H, Fonkalsrud E. Reducction of postinfusion venous endothelial injury with intralipid. Sur Gynecol Obstet 1984; 158:57-65.

40. Maki DG, Ringer M. Risk factors for infusion-related phlebitis with small peripheral venous catheters. Am Col Physi 1991; I I 4(10):845-854

41. Stefanini E. Estabelecimento e manutenção das vias de infusão de medicamentos: In: Timerman S. Novas tendências no manuseio farmacológico na ressuscitação cardíaca e pulmonar. São Paulo: Lemos Editorial; 2000. p. 32-48.
42. Rocha EAV, Souza C. Avaliação hemodinâmica de anastomoses arteriais reforçadas com selantes de fibrina: estudo experimental em suínos. Braz I Cardiovasc Surg 2007; 22(1): 81-6.

43. Arreguy-Sena C, Carvalho EC. Risco para Trauma Vascular: diagnóstico de Enfermagem? In: Anais do VII Simpósio Nacional de Diagnósticos de Enfermagem. 2004. Belo Horizonte (MG), Brasil. Belo Horizonte: ABEn-MG; 2004. p. 148.

44. Schumacher WA, Heran CL. Effect of thromboxane receptor antagonists on venous thrombosis in rats. I Pharm Exp Therap 1989: 248(3): 1109-1115.

45. Kapsch DN, Adelstein EH, Rhodes GR, Silver D. Heparininduced thrombocytopenia, thrombosis and hemorrage Surgey 1979; 86(1): 148-55.

46. Johnson JV, Jeske AH, McDaniel KH, Herrera GQ. Development of an in vivo model for assessment on drug-induced vascular injury. I Oral Maxilofac Surg 1989; 47: 819-22.

47. Associação Brasileira de Normas Técnicas- ABNT. EB1998. Plásticos de polietileno para artigos médicos, odontológicos e hospitalares de uso único. Rio de Janeiro: ABNT; 1989.

48. Associação Brasileira de Normas Técnicas- ABNT. EB2 117. Recipientes plásticos para soluções parenterais de grandes volumes. Rio de laneiro: ABNT; 1991.

49. Associação Brasileira de Normas Técnicas- ABNT. NBRI 4041. Equipo de infusão estéril de uso único. Rio de Janeiro: ABNT; 1998.

50. Associação Brasileira de Normas Técnicas- ABNT. NBR9752 Seringas de plástico estéreis e de uso único. Rio de Janeiro: ABNT; 1997.

51. Associação Brasileira de Normas Técnicas- ABNT. NBR9753. Escalpe estéril e de uso único- requisitos e métodos de ensaio. Rio de Janeiro: ABNT; 1997.

52. Associação Brasileira de Normas Técnicas- ABNT. NBR9259. Agulha hipodérmica estéril e de uso único. Rio de Janeiro: ABNT; 1997.

53. Brewer JH, Bryant HH. The toxicity and safety testing of disposable medical and pharmaceutical materials. J Am Pharm Assoc 1960; 49(10): 625-6.

54. Maeda ST. Escalpe, equipo de soro e seringa descartável: critérios para subsidiar a compra [dissertação]. São Paulo; Escola de Enfermagem, Universidade de São Paulo; 1998. 